\title{
A Survey of the quantity and type of biological aerosols in selected wards of a teaching hospital in Ghazvin
}

\author{
Akbar Eslami ${ }^{1}$, Fatemeh Karimi ${ }^{2}$, Zainab Karimi ${ }^{3}$, Zahra Rajabi ${ }^{4}$
}

${ }^{1}$ Environmental and Occupational Hazards Control Research Center, Shahid Beheshti University of Medical Sciences, Tehran, Iran

${ }^{2}$ Department of Environmental Health Engineering, School of Public Health, Shahid Beheshti University of Medical Sciences, Tehran, Iran

${ }^{3}$ Department of Environmental Health Engineering, School of Public Health, Qazvin University of Medical Sciences, Qazvin, Iran

${ }^{4}$ Vice Chancellery of Treatment, Qazvin University of Medical Sciences, Qazvin, Iran

\section{Type of article: Original}

\begin{abstract}
Introduction: Bioaerosols are agents that can cause infection, allergy or induce other toxic effects in the human body. If the person exposed to such particles is not capable of their destruction or elimination from the body, the established chemical and physiological disorders can result in disease or death. The aim of this study was to assess the concentrations of bioaerosols in several wards of a teaching hospital.

Methods: Given that gas air-conditioners (split and window types) were used for ventilation in the eye operating room, internal intensive care unit, and the respiratory isolation room, these wards were selected for passive sampling. Sterile plates containing culture medium were exposed for two hours to the wards' indoor ambient air. After this time, they were transferred to a lab to undergo incubation, colony count, and identification of the microorganisms. The data were analyzed using SPSS software, version 18, and the significance level of less than 0.05 was used.

Results: Based on our findings, the highest colony-forming bacterial unit was observed $22 \mathrm{cfu} / \mathrm{plate} / \mathrm{h}$ in the eye operating room and, the highest colony-forming fungal unit was observed $4 \mathrm{cfu} / \mathrm{plate} / \mathrm{h}$ in the internal intensive care unit. Based on the results of the differential tests, the most prevalent bacteria identified were Staphylococcus epidermidis $(75 \%)$ in the air of eye operating room and Staphylococcus saprophyticus $(52 \%)$ in the internal intensive care unit and isolation room. The most prevalent identified fungi in the air of selected wards were related to Alternaria alternata (43\%), Aspergillus flavus (24\%), Penicillium (36\%) and Curvularia (21\%) types. Based on Spearman's correlation test, no significant relationship was observed between the factor of temperature and the number of fungal and bacterial colonies $(\mathrm{r}=0.201, \mathrm{p}=0.42 ; \mathrm{r}=-0.197, \mathrm{p}=0.41)$. Moreover, a meaningful relationship was observed only between the number of individuals and the bacterial colonies present in the air $(\mathrm{r}=0.749, \mathrm{p}=0.0001)$.

Conclusion: Comparing the number of diagnosed colonies by $25 \mathrm{cfu} / \mathrm{plate} / \mathrm{h}$ value showed that the numbers of colonies in all samples were lower than the mentioned values. So, the air-conditioning systems' performance in reducing the number of bioaerosols in the studied wards was satisfactory. However, since the remaining bacterial and fungal contamination can cause serious infections in patients, it is highly necessary that the cleaning intervals and replacement time points of such filters be programmed based on the number of individuals present in the wards and their active surgical hours.
\end{abstract}

Keywords: bioaerosol, hospital, air-conditioning, indoor air

\section{Corresponding author:}

Fatemeh Karimi, Department of Environmental Health Engineering, School of Public Health, Shahid Beheshti University of Medical Sciences, Tehran, Iran. Tel.: +98.9128826838, E-mail: mahkar1393@gmail.com

Received: December 04, 2015, Accepted: February 21, 2016, Published: April 2016

iThenticate screening: February 21, 2016, English editing: March 26, 2016, Quality control: April 02, 2016

(C) 2016 The Authors. This is an open access article under the terms of the Creative Commons Attribution-NonCommercialNoDerivs License, which permits use and distribution in any medium, provided the original work is properly cited, the use is non-commercial and no modifications or adaptations are made. 


\section{Introduction}

Bioaerosols are referred to the agents that are transferred by air currents. They include live microorganisms, such as bacteria, viruses, fungi, and their metabolites, e.g., endotoxins (1-4). Among the most important microorganisms that cause diseases through air currents are Aspergillus, Penicillium species, Legionella pneumophila, Francisella tularensis, Bacillus anthracis, Yersinia pestis, Trichomonas, Variola virus, and Mycobacterium tuberculosis (2). Influenza A virus and other types of viruses also can be transmitted through air currents (5). There is enough evidence to confirm the airborne transfer of various agents, such as Mycobacterium tuberculosis, Mycobacterium africanum, measles, and chicken pox (6). Furthermore, certain evidence exists that proves the airborne transmission of mumps, bacterial meningitis, and pertussis. Other pathogens, such as smallpox (6), methicillin-resistant staphylococcus aureus (4), Legionnaires disease, and Pseudomona aeruginosa also can be transmitted through multiple routes (6). The quality of the hospital's air is considered an important risk factor for the health of the staff and patients (7). If the air quality is undesirable, it can result in the transmission of nosocomial infections (8), sickhospital syndrome, and other occupational hazards (9) in immunodeficient individuals (4). Nosocomial infections impose heavy costs on the health system, particularly in developing nations $(2,10)$. Around 7.1 million nosocomial infections and 99,000 cases of related deaths are reported in the United States annually $(2,11)$. Surgical infections are one of the main problems of modern medicine. They consist of both superficial and deep types. The treatment of deep infections is complex and difficult, and they may result in re-operation or may put the patient's life at risk (6). Marceloukinti reported different fungi, including Penicillium, Aspergillus, Mucor, and Alternaria, in a study of the air quality in the ophthalmology ward of a hospital in Athens. Kelkar also believed that post-surgical infections may be caused by the entrance of fungal spores by air-conditioning systems (11). In the many studies that have been performed focusing on the transmission of infectious diseases by airborne particles, air-ventilation has been referred to as one of the principle techniques in reducing and controlling the spread of infectious agents through air in hospitals. Li et al. (2007) studied the role of air-ventilation systems in disease transmission among individuals, and they reported that there was a very close relationship between them (6). Chuaybemroong et al. also showed that high levels of ventilation reduce the amount of airborne bacteria by diluting the air $(7,12)$. Various studies have shown that bone surgery in an operating room (OR) with a highly clean air equipment results in reduced rates of postsurgical infections (6). However, if the air ventilation is inadequate or inefficient, it will, on its own, result in air contamination (13). In the study conducted by Ghorbani et al. on the variety and density of bioaerosols in the operating room, they reported a much higher level of bioaerosols than the recommended level. In the latter study, the researchers concluded that the ventilation systems used in the operating rooms were inefficient and required reform and redesign $(4,14)$. Therefore, monitoring of the bioaerosols present in hospitals' indoor air, particularly intensive care units and operating rooms, seems essential in order to epidemiologically study nosocomial infections, the quality and quantity of bioaerosols, and their control route. The aim of the present study was to determine the quality and quantity of airborne microorganisms in the eye operating room, internal intensive care unit, and the respiratory isolation room of the hospital. In all of the three mentioned wards, gas air-conditioners (split and window types) were used for ventilation. We hope that the findings of the present study will help in the better control and more efficient management of air quality inside hospital wards.

\section{Material and methods}

This cross-sectional study was conducted in one of teaching hospitals in Ghazvin University of Medical Sciences during May and June 2015. Air samples were collected in the eye operating room, internal intensive care unit, and respiratory isolation room using the passive sampling method. In all of the three selected wards, air-conditioning systems (with air vent filters) were used. Nutrient agar culture medium was used for the growth and counting of all bioaerosols, whereas Sabouraud dextrose agar medium containing chloramphenicol was used for the growth and counting of fungal colonies. The culture media were provided under sterile conditions in the lab. All plates were placed at a distance of $1.5 \mathrm{~m}$ from the floor, the walls, and the patients' beds.

The sampling time was decided as two hours on average. After this time, the plates were transferred to the lab under controlled conditions. While sampling, the room temperature and the number of individuals in the sampling location were recorded. Plates containing nutrient agar were placed in a $35{ }^{\circ} \mathrm{C}$ incubator for $48-72 \mathrm{hr}$, whereas a $30{ }^{\circ} \mathrm{C}$ incubator was used for the Sabouraud dextrose plates for 5-7 days. After the mentioned time, the bacterial and fungal colonies were counted, and the numbers of bacterial and fungal colonies were reported based on cfu/plate/h. Since no standard or guideline for the concentration of bioaerosols has been established in Iranian scientific documentation, the standards of the Swiss Hospital Association were used to assess the number of colonies. Based on this standard, the number of colonies must be $\leq 25 \mathrm{cfu} /$ plate/h in active operating rooms $(5,15)$. In order to identify bacteria, their morphology, gram-staining, endospore formation, and catalase and oxidase activities were 
used. Fungal identification was based on morphology and secondary culture characteristics. The data that were obtained were analyzed by the Kruskal-Wallis and Spearman's tests using SPSS software, version 18.

\section{Results}

In this study, 37 air samples were taken to determine the bacterial and fungal bioaerosol contamination in the eye operating room, internal intensive care unit, and the respiratory isolation room. As shown in Table 1, the most and least prevalent bacterial colonies identified were related to the internal intensive care unit and eye operating room as $22 \mathrm{cfu} / \mathrm{plate} / \mathrm{h}$ and $1 \mathrm{cfu} / \mathrm{plate} / \mathrm{h}$, respectively. The values for fungal colonies were $4 \mathrm{cfu} / \mathrm{plate} / \mathrm{h}$ in the internal intensive care unit and $0 \mathrm{cfu} / \mathrm{plate} / \mathrm{h}$ in the eye operating room. Statistical analyses of the results indicated that there was a significant difference in the number of identified bacteria present in the indoor air of different wards $(\mathrm{p}=$ 0.004). However, no meaningful difference was observed regarding the number of identified fungi in the same wards $(\mathrm{p}=0.74)$. Given the results of the differential tests, as shown in Table 2, the highest percentage of observed bacteria in the eye operating room was related to Staphylococcus epidermidis (75\%) and Staphylococcus saprophyticus (25\%). The highest numbers of identified fungi were Alternaria alternata $(43 \%)$ and Aspergillus flavus $(24 \%)$. In the indoor air of the internal intensive care unit and respiratory isolation room, the most prevalent bacteria were Staphylococcus saprophyticus (52\%) and Staphylococcus epidermidis (36\%), whereas the most prevalent fungi detected were Penicillium (36\%) and Curvularia clavata $(21 \%)$. Based on Spearman's correlation test, no significant relationship was observed between the factor of temperature and the number of fungal and bacterial colonies $(r=0.201, p=0.42 ; r=-0.197, p=0.41)$. Moreover, when considering the two variables of number of individuals present at the sampling location and the amount of bioaerosols, a meaningful relationship was only observed between the number of individuals and the bacterial colonies present in the indoor air $(r=0.749, p=$ $0.0001)$.

Table 1. Most- and least-prevalent bacterial and fungal colonies in the wards studied in the selected hospital

\begin{tabular}{|l|l|l|l|}
\hline Ward & Dispersion & Bacterial colonies, cfu/plate/h & Fungal colonies, cfu/plate/h \\
\hline Operating room & Max & 22 & 2 \\
\cline { 2 - 4 } & Min & 7 & 0 \\
\hline Internal intensive care unit & Max & 9 & 4 \\
\cline { 2 - 4 } & Min & 1 & 1 \\
\hline Isolation room & Max & 20 & 2 \\
\cline { 2 - 4 } & Min & 6 & 1 \\
\hline
\end{tabular}

Table 2. Isolation frequency of airborne bacteria and fungi (\%) in surveyed wards in the selected hospital

\begin{tabular}{|l|l|l|l|l|}
\hline Isolates & $\begin{array}{l}\text { Eye operating } \\
\text { room }\end{array}$ & $\begin{array}{l}\text { Intensive care } \\
\text { unit }\end{array}$ & $\begin{array}{l}\text { Isolation } \\
\text { room }\end{array}$ \\
\hline \multirow{3}{*}{ Bacterial genus and species } & Staphylococcus saprophyticus & 25 & 52 & 52 \\
\cline { 2 - 5 } & Staphylococcus epidermidis & 75 & 36 & 36 \\
\cline { 2 - 5 } & Others & - & 12 & 12 \\
\hline \multirow{5}{*}{ Fungal genus and species } & Alternaria alternata & 43 & - & - \\
\cline { 2 - 5 } & Penicillium corylophilum & - & 36 & 36 \\
\cline { 2 - 5 } & Aspergillus flavus & 24 & - & - \\
\cline { 2 - 5 } & Curvularia clavata & - & 21 & 43 \\
\cline { 2 - 5 } & Others & 33 & 43 & \\
\hline
\end{tabular}

\section{Discussion}

The findings of the current study showed that the bacteriological quality of the air samples obtained from all the studied wards was less than the acceptable value of $25 \mathrm{cfu} / \mathrm{plate} / \mathrm{h}$. Therefore, the microbial status of the mentioned wards was assessed as satisfactory. When comparing the different hospital wards with each other, the highest bacterial contamination rate was in the eye operating room, with a mean of $22 \mathrm{cfu} / \mathrm{plate} / \mathrm{h}$; the reason may be the higher number of individuals in the smaller area of the mentioned ward. Mirbahar et al. (2005) corresponded the higher bacterial load of different wards of Sukkur Hospital to the poor ventilation and high individual flows in such sectors (16). In the current study, the highest fungal contamination was related to the internal intensive care unit with a mean of $4 \mathrm{cfu} / \mathrm{plate} / \mathrm{h}$, which may have been due to the two active doors in the ward combining indoor air with outdoor air. Goyer et al. in the Guideline on Bioaerosols Evaluation, Control, and Prevention stated that bacterial contamination of indoor air originates from within such environments, since as the bacterial concentration 
of the outside air is much lower than the inside air. However, the fungal concentration of the indoor air is in contact with the outdoor air, and, if the ventilation system is inefficient in reducing the microbial concentration, the concentration of airborne fungi will increase subsequently (17). In the present study, the highest prevalence among bacterial colonies was related to the Staphylococcus types. Our findings corresponded with those of Abdullahi et al., who reported the most common microorganisms in the indoor air of different wards of Valiasr hospital in Tehran, Iran to be micrococcus and Staphylococcus types (10). Hoseinzadeh et al. (2011) studied the bacterial and fungal aerosols of different hospitals in Malayer City, Iran, and they reported Coagulase-negative Staphylococci, Micrococcus, Bacillus, Staphylococcus aureus as the most common bacterial colonies (2). Based on our findings, the highest percentage of identified fungi in the eye operating room were Alternaria alternata and Aspergillus flavus, whereas the Penicillium and Curvularia fungi were more common in the internal intensive care unit and respiratory isolation room. Our findings are in agreement with those reported from Zanjan Hospital in Iran, mentioning Aspergillus, Alternaria, Penicillium, Fusarium, and Cladosporium as the most prevalent fungi in their special wards (18). The concentrations of biological aerosols in different wards of the hospitals affiliated to Esfahan University of Medical Sciences conducted by Noormoradi et al. also were in line with our findings. They reported Penicillium and Black fungus as the most prevalent fungi, which also had a high concentration in the outdoor air surrounding the hospital. The most common indoor bacterial aerosol was reported as Coagulase-negative Staphylococci (5).

\section{Conclusions}

Given the results that were obtained, the air vent filters of the air-conditioning systems used in the different wards seem to be efficient in reducing the microbial load. However, as the remaining bacterial and fungal contamination can cause serious infections in the patients, it is highly necessary that the cleaning intervals and replacement time points of such filters be programmed based on the number of individuals present in the wards and their active surgical hours.

\section{Acknowledgments:}

The authors received no financial support for the research, authorship, and publication of this article. The efforts of officials, hospital staff, and all others who helped the researchers in this study are appreciated.

\section{Conflict of Interest:}

There is no conflict of interest to be declared.

\section{Authors' contributions:}

All authors contributed to this project and article equally. All authors read and approved the final manuscript.

\section{References}

1) Chubineh AR, Rostami R, Tabataabae SHR. Assessment of Bioaerosols Types and Concentration in Ambient Air of Shiraz University of Medical Sciences Educational Hospitals in 2008. Iran Occupational Health. 2009; 6(2): 69-76.

2) Hoseinzadeh E, Taghavi M, Samarghandie MR. Evaluation of Fungal and Bacterial Aerosols in The Different Wards of Malayer City's Hospitals in 2011-2012. Hospital. 2014; 13(3): 99-108.

3) Griffiths W., Decosemo GAL. The Assessment of Bioaerosols: A Critical Review. Journal of Aerosol Science. 1994; 25(8): 1425-58. doi: 10.1016/0021-8502(94)90218-6.

4) Setlhare G, Malebo N, Shale K, Lues R. Identification of Airborne Microbiota in Selected Areas in a Health-Care Setting in South Africa. BMC Microbiol. 2014; 14: 100. doi: 10.1186/1471-2180-14-100, PMID: 24750818, PMCID: PMC4016773.

5) Napoli C, Marcotrigiano V, Montagna MT. Air Sampling Procedures to Evaluate Microbial Contamination: A Comparison Between Active and Passive Methods in Operating Theatres. BMC Public Health. 2012; 12: 594. doi: 10.1186/1471-2458-12-594, PMID: 22853006.

6) Memarzadeh F, Xu W. Role of Air Changes per Hour ( $\mathrm{ACH})$ in Possible Transmission of Airborne Infections. Journal of Build Simul. 2012; 5: 15-28. doi: 10.1007/s12273-011-0053-4.

7) Jung $\mathrm{CC}, \mathrm{Wu} \mathrm{PC}$, Tseng $\mathrm{CH}$, Su HJ. Indoor Air Quality Varies with Ventilation Types and Working Areasin Hospitals. Journal of Building and Environment. 2015; 85: 190-5. doi: 10.1016/j.buildenv.2014.11.026.

8) Beggs CB, Kerr KG, Noakes CJ, Hathway EA, Sleigh PA. The ventilation of multiple-bed hospital wards: Review and analysis. Am Journal of Infection Control. 2008; 36(4): 250-9. doi: 10.1016/j.ajic.2007.07.012, PMID: 18455045. 
9) Nourmoradi H, Nikaeen M, Amin MM, Hatamzadeh M. An Investigation on Bio-aerosol Concentrations in the Different Wards of Hospitals of Isfahan University of Medical Sciences. Journal of Isfahan Medical School. 2011; 29(149): 1028.

10) Abdollahi AR. Concurrence of Nosocomial Infections with Microorganisms Spreading in the Air of Hospital Wards. Medical laboratory Journal. 2010; 3(2): 47-52.

11) Azizifar M, Jabari H, Nadafi K, Nabizadeh R, Tabaraei Y, AzamSolgi A. A Qualitative and Quantitative Survey on Air-Transmitted Fungal Contamination in Different Wards of Kamkar Hospital in Qom Iran in 2007. Qom University of Medical Sciences Journal. 2009; 3(3): 25-30.

12) Chow TT, Yang XY. Ventilation Performance in Operating Theatres Against Airborne Infection: Review of Research Activities and Practical Guidance. Journal of Hospital Infection. 2004; 56: 85-92. doi: 10.1016/j.jhin.2003.09.020, PMID: 15019218.

13) Wan GH, Chung PP, Tang CS. Long-term Surveillance of Air Quality in Medical Center Operating Rooms. Am J Infect Control. 2011; 39(4): 302-8. doi: 10.1016/j.ajic.2010.07.006, PMID: 21256628.

14) Khawcharoenporn T, Apisarnthanarak A, Thongphubeth K, Yuekyen C, Damnin S, Hayden MK, et al. Post-Flood Measurment of Fungal Bio-Aerosol in a Resource-Limited Hospital: Can The Settle Plate Method Be Used?. Journal of Hospital Infection. 2013; 83: 150-2. doi: 10.1016/j.jhin.2012.11.012.

15) Masoumbeigi H, Esmaeili D, yamchi H, Sepandi M. Survey of Air Bacteriological Contamination Rate in One of the Hospital's Dentistry Centers in Tehran. Iran Journal of Med Microbio. 2015; 9(2): 73-8.

16) Mirbahar AM, Memon BA. Bacteriological Monitoring through Air Sampling in Different Locations of Teaching/Civil Hospital Sukkur. Journal of App Em Sc. 2005; 1(2): 13-5.

17) Verde SC, Almeida SM, Matos J, Guerreiro D, Meneses M, Faria T, et al. Microbiological Assessment of Indoor Air Quality at Different Hospital Sites. Res Microbiol. 2015; 166(7): 557-63. doi: 10.1016/j.resmic.2015.03.004, PMID: 25869221.

18) Noorian AA, Badali H. Studying the fungi contaminating the air, the operating room equipment and certain wards of Zanjan city hospitals. Journal of Zanjan University of Medical Sciences and Health Services. 2011;36: 9-16. 